\title{
A New Trisaccharide in Tobacco Seeds
}

Sir :

In the course of our investigation on the sugars of tobacco seeds, a new trisaccharide, $\alpha-$ glucosido- $\beta$-fructosido- $\alpha$-galactoside, has been found by the method of paper chromatography, using $n$ butanol-acetic acid-water ${ }^{1)}$, phenol-water ${ }^{2)}$, and pyridine- $n$-butanol-water ${ }^{3}$ ) as solvents. Filter paper Toyo No. 2 was employed. Spots on the paper chromatograms were revealed by using the benzidine and resorcinol reagents.

Benzidine reagent : $0.5 \mathrm{~g}$. benzidine, $20 \mathrm{cc}$. galacial acetic acid, $80 \mathrm{cc}$. ethanol.

Resorcinol reagent : $0.5 \mathrm{~g}$. resorcinol, $20 \mathrm{cc}$. $50 \%$ trichloracetic acid, $80 \mathrm{cc}$. ethanol.

The methanolic extract of tobacco seeds (Nicotiana tabacum L., "Bright Yellow") was concentrated in vacuo to the syrup which was dissolved in water. After treating the aqueous solution with lead acetate, the formed precipitate was removed by centrifugation. The supernatant was treated with hydrogen sulfide. After removing lead sulfide by filtration, the filtrate was concentrated to a small volume in vacuo. A small portion of it was separated on the paper chromatogram.

The chromatogram yielded no spot with the benzidine reagent, but two spots with the resorcinol reagent, the one ( $\mathrm{Rf}=0.11$ in $n$-butanol-acetic acid-water $\left.{ }^{1}\right)$ corresponding to an authentic sucrose and the other $(R f=0.019)$ not corresponding to raffinose $(R f=0.025)$ and stachyose $(\mathrm{Rf}=0.003)$.

The material corresponding to the latter spot was extracted with $80 \%$ ethyl alcohol from the chromatograms on number of spots have been run simultaneously. After concentrating the extract in vacuo, the residue was then hydrolyzed with $2 \%$ sulfuric acid, $5 \%$ oxalic acid or $\boldsymbol{\alpha}$-galactosidase and each hydrolysis product was rechromatographed by the same procedure.

Table I

\begin{tabular}{|c|c|c|c|c|c|}
\hline \multirow[b]{2}{*}{ Suger } & \multirow[b]{2}{*}{ Phenol-water ${ }^{2}$ ) } & \multicolumn{2}{|c|}{ Rf value } & \multicolumn{2}{|c|}{ Reaction to } \\
\hline & & $\begin{array}{l}n \text {-Butanol- } \\
\text { acetic acid- } \\
\text { water') }\end{array}$ & $\begin{array}{l}\text { Pyridine- } \\
\text { n-butanol- } \\
\text { waters) }\end{array}$ & $\begin{array}{c}\text { Ben- } \\
\text { zidine }\end{array}$ & $\begin{array}{l}\text { Resor- } \\
\text { cinol. }\end{array}$ \\
\hline Fructose & 0.51 & 0.23 & - & + & + \\
\hline Glucose & 0.39 & 0.17 & 0.37 & + & - \\
\hline Galactose & 0.42 & 0.16 & 0.33 & + & - \\
\hline Sucrose & 0.40 & 0.11 & - & - & + \\
\hline Lactose & - & 0.06 & - & + & - \\
\hline Raffinose & 0.29 & 0.025 & - & - & + \\
\hline Stachyose & 0.15 & 0.003 & - & - & + \\
\hline "Disaccharide" & 0.38 & 0.07 & - & + & + \\
\hline "Trisaccharide" & 0.19 & 0.019 & - & - & + \\
\hline
\end{tabular}

Table Il

Hydrolysis Products of the Trisaccharide

$\begin{array}{cll}\text { With } & 2 \% \mathrm{H}_{2} \mathrm{SO}_{4} & \text { Glucose, Gaiactose and Fructose } \\ \prime \prime & 5 \% \text { Oxalic acid } & \text { Glucose and Disaccharide (Fructose-Galactose) } \\ \prime \prime & \propto \text {-Galactosidase } & \text { Sucrose and Galactose }\end{array}$

Sulfuric acid hydrolysis yielded glucose, fructose and galactose. With oxalic acid small amounts of galactose and fructose were formed; but main products were glucose and an unknown sugar which was found to be a disaccharide consisting of fructose and galactose after the $2 \%$ sulfuric acid hydrolysis. The $R f$ value of the disaccharide $(R f=0.07)$ was between that of lactose $(R f=0.06)$ and sucrose $(R f=0.11)$ and the color reaction to the spraying reagents was different from those of the above two disaccharide. The trisaccharide treated with $\alpha$-galactosidase from seeds of Pinus Thubergii, ParLtore gave mainly sucrose and galactose.

From these evidences, the new trisaccharide seemed to be $\alpha$-glucosido- $\beta$-fructosido- $\alpha$-galactoside, glucose and fructose linking in the form of sucrose. This trisaccharide has not yet been reported to occur in the plant kingdom.

The Central Research Institute,

The Japan Monopoly Corporation, Tokyo, Japan

Einosuke WADA

Received March 30, 1951

Kyaji YAMAZAKI

1) Partridgh, S. M.: Nature, 168,270 (1946)

2) Wolfson, W, Q., Cohn, C. and Devancey, W. A.: Science, 109, 541 (1949)

3) Chargaff, E., Levine, C. and Grgen, C.: J. Biol. Cldem., 176, 67 (1948) 